\title{
Foreign Language Classroom Anxiety and Learners' and Teachers' Beliefs toward FLL: A Case Study of Iranian Undergraduate EFL Learners
}

\author{
Tina Toghraee (Corresponding author) \\ English Department, Shahreza Branch, Islamic Azad University, Isfahan, Iran \\ E-mail: t_toghraei@yahoo.com \\ Mohsen Shahrokhi \\ English Department, Shahreza Branch, Islamic Azad University, Isfahan, Iran \\ E-mail: shahrokhi1651@yahoo.com
}

Received: 30-10-2013

doi:10.7575/aiac.ijalel.v.3n.2p.131
Accepted: $12-12-2013$

Published: 01-03-2014

\begin{abstract}
This study was an attempt to determine the beliefs of undergraduate female and male EFL learners at Shahreza University, Isfahan, Iran, about foreign language classroom anxiety, and compare students' and teachers' attitudes toward FLL. For this purpose sixty linguistically homogeneous female and male students were selected after administering the QPT, and were given BALLI and FLCAS questionnaires designed by Horwitz (1987). Fifteen EFL instructors were selected to answer the BALLI questionnaire, and then the data from the two questionnaires were statistically analyzed with correlational analysist-tests. The findings revealed hat, first, there was a positive and statistically significant correlation between Iranian university students' beliefs about FLL and their level of class anxiety; second, that teachers and students hold mostly different beliefs about FLL, despite some similar beliefs; and finally, male and female participants did not hold the same ideas regarding class anxiety and beliefs about FLL. The results of this study confirmed previous research findings in this area.
\end{abstract}

Keywords: foreign language anxiety, beliefs about language learning, FLCAS, BALLI, university EFL learners.

\section{Introduction}

Although a great deal of research has been conducted on foreign language anxiety and beliefs toward FLL, little research has been done on the relationship between these two variables among male and female learners and there is even less research about the beliefs of teachers toward foreign language learning. Since the1970s anxiety has been considered and studied as an important affective variable. Horwitz (1986 cited in Talebinejad and Nekouie, 2013) defined anxiety as the feeling of tension, apprehension, and nervousness accompanied by a symptom of the automatic nervous system. Brown (1994) referred to anxiety as the feeling of "uneasiness, frustration, self-doubt, apprehension, or worry." Generally, anxiety is a complex psychological term covering many variables. Simply defining, it is "a general feeling of apprehension including hyper-vigilance, increased sympathetic nervous system activity, and difficulty concentrating" (Davu and Palladino, cited in Subaş1 2010). Scovel (1978) defined anxiety as "a state of apprehension, a vague fear" (p.131). Anxiety is an emotional state that can have both positive and negative influences which can foster or hinder an action such as learning (MacIntyre, 1995).

To investigate, clarify, and measure the foreign language anxiety, Horwitze, Horwitze and Cope (1986) suggested a scale called the foreign language classroom anxiety scale, or FLCAS.It isa "self-report" instrument which determines the amount of anxiety which has been proven or shown by negative performance experiences and social comparisons, psycho-physiological symptoms, and avoidance behaviors (Horwitz, 1986 cited in Talebnejad and Nekouei, 2013). FLCASis constructed based on 33 questions and the respondents are asked to respond to the question items which are in fact related to situations particularly relevant to foreign language anxiety and all these items reflect the characteristics of such an anxiety.

The major research on language learning beliefs was done by Elaine Horwitz in the 1980s at the University of Texas at Austin. She developed the Beliefs about Language Learning Inventory (BALLI) which is a means to determine teachers' and students' attitudes toward a variety of issues related to language learning (Talebnejad and Nekouei, 2013). This instrument has been used by many researchers to assess learners' beliefs (Nikitina and Furuoka, 2006). Horwitz (1985, cited in TalebnejadandNekouei, 2013) described the BALLI helpful because as she said it helps the teachers not only to determine popular and common beliefs of their students but also to identify minor groups or individuals with differing ideas.

The process is that, during a series of researches in different years, Horwitz developed three different kinds of BALLI. The first one was the teachers' version of the BALLI (teachers BALLI) in 1985 which was aimed at measuring 
instructors' beliefs in four main areas: foreign language aptitude, the difficulty of language learning, the nature of language learning, and appropriate language-learning strategies. The second version of BALLI was suggested in (1987) to determine the students' beliefs about the language learning process and the nature of language. This version consisted of 34 items across five main areas: foreign language aptitude, the difficulty of language learning, the nature of language learning, learning and communication strategies, and motivations. Finally in 1988 she suggested the last version of her BALLI to assess the beliefs of the American foreign language learning students about language learning. As mentioned earlier BALLI has teacher and student versions in different item numbers but what is common is that each item has a five-point Likert scale ranging from 1 (strong agreement) to 5 (strong disagreement) (Talebnejad and Nekouei, 2013).

MacIntyre and Gardner (1994, p. 284, cited in Subaş1, 2010) defined language anxiety as "the feeling of tension and apprehension specifically associated with second language texts, including speaking, listening, and learning". Hurd (2007cited in Mak (2011)believes that language anxiety has become a major element of any examination of factors contributing to learning process and learner achievement while Arnold and Brown (1999 cited in Mak, 2011) believe that anxiety in language learning might be regarded as the most pervasive obstruction to the learning process. The origin of foreign language anxiety has been explained as the inherent inauthenticity associated with immature second language communicative abilities, by Horwitz, 2001 (cited in Subaş1 2010). Yousefi, Azarfam and Baki (2012) have mentioned that Language anxiety involves three connected anxieties: communication apprehension; test anxiety; and fear of negative evaluation. It is clear that a foreign language class can be more anxiety-provoking than any other course for many students (Liu, 2007; Ohata, 2005).

Some of the studies in the field of anxiety have shown a negative relationship between anxiety, beliefs and language achievement, and some other studies have reported neutral or even positive relationship between these variables. Forexample, Talebinejad and Nekouie (2013) conducted a two-phase survey to investigate the relationship between foreign language anxiety and beliefs about foreign language learning among children in a language institute in Shahreza in Iran.

Gomari and Lucas (2013) had a study which was conducted in Manila, the capital city of the Philippines, and the subjects were selected from four different private universities in Metro Manila. The primary basis for selecting these schools was the sizable population of Iranian undergraduate students who were pursuing their studies there.

The results of the FLCAS survey showed that Iranian EFL learners in the Philippines generally experience anxiety while learning the English language. The primary source of anxiety for Iranian EFL learners in this study was Test Anxiety. This was followed, respectively, by Communication Apprehension, English Classroom Anxiety, and Fear of Negative Evaluation. Serraj and Noordin (2013) examined whether Anxiety was an influential factor in a foreign language learning domain and whether it played a crucial role in language learners' performance or not. The study revealed that there was a negative correlation between FLLA and listening comprehension and a negative correlation between FLA and listening comprehension whereas FLA and FLLA enjoyed a positive correlation. It could be concluded that the relationship between Foreign Language Anxiety and Foreign Language Listening Anxiety of the participants were in accordance with each other. Furthermore the result showed that the impact of FLLA on Iranian students' listening comprehension skill was significantly more problematic.

The major purpose of this study is to examine foreign language anxiety and its relation to beliefs toward foreign language learning among male and female EFL learners. Moreover, it aims at comparing the learners' beliefs with the beliefs of EFL teachers. More specifically, in this study, in order to investigate the effect of FL anxiety on beliefs of male and female foreign language learners, FLCAS was employed, and to consider the beliefs of learners and teachers and comparing them, BALLI was used.

\section{Statement of the Problem}

Although a great deal of research has been conducted on foreign language anxiety and beliefs toward FLL, little research has been done on the relationship between these two variables among male and female learners and there are even fewer studies about the beliefs of teachers toward foreign language learning.

\section{Purpose of the study}

Reviewing the related literature reveals that the findings of this study may clarify three points: one is the effect of foreign language anxiety on male and females' belief about foreign language learning, the other one is the existence of any possible differences in the beliefs of opposite gender learners toward foreign language learning and, the last one is the existence of any possible differences between teachers' attitudes toward foreign language learning and learners' attitudes. Each of these findings may bring new attitudes toward foreign language learning and teaching, at least in terms of the chosen learning and teaching methodologies; therefore, it is expected that the findings of this study shed light on foreign language pedagogy in Iran. The main focus of this study was on EFL university learners in Iranian context.

\section{Research questions}

This study was an attempt to investigate theabove-mentioned problems:

1. Is there any relationship between Iranian university students' level of anxiety and their beliefs toward FLL?

2.Is there any significant difference between university learners' beliefs about FLL and those of their teachers?

3.Is the relationship between learners' anxiety level and beliefs toward foreign language learning different in male students and female students? 


\section{Research hypotheses}

Based on the questions cited above, this study aimed at testing the following null hypotheses:

H01. There is no relationship between Iranian university students' level of anxiety and their beliefs about FLL.

H02. There is no significant difference between Iranian university students' beliefs about FLL and those of their teachers.

H03. There is no difference between male students' and female students' anxiety level and beliefs toward FLL

\section{Significance of the Study}

The results can be useful for those teachers who deal with different genders in different foreign language contexts especially university classes in that they can seek ways to change or remove the negative FLL beliefs of their students. The results would also be beneficial especially for parents with children who hate foreign language learning; in fact parents can find the roots of this hatred, perhaps one of them is anxiety, and treat it appropriately instead of constant punishment and complaint.

\section{Methodology}

\subsection{Participant}

The study took benefit of two main groups of participants, that is, teachers and students. Regarding the students group, in the beginning, 130 sophomores majoring either in English language teaching or translation at Shahreza Branch, Azad University were given a Quick Placement Test (QPT) in order to select 60 homogeneous students with intermediate level of English proficiency ( 30 males and 30 females). The students were all native speakers of Farsi and their ages ranged between 19 and 25 .

Regarding the teachers group, 15 university professors (both male and female) who were teaching English at Shahreza University were also asked to complete the questionnaires. These professors were mostly lecturers and few of them were assistant professors. Their year of teaching experience ranged between 3 and 15 years, and they were between 26 and 40 years of age.

\subsection{Instruments}

\subsubsection{The QPT}

In order to control the proficiency factor, there was a need to homogenize the participants according to their level of L2 proficiency. To do so the Quick Placement Test (QPT) was used to select the intermediate group.

\subsubsection{Foreign Language Classroom Anxiety Scale (FLCAS) Questionnaire}

As its name suggests, this questionnaire was meant to find out the opinion of the respondents regarding FL classroom anxiety (see Appendix B). It contains 33items. The score of these 33 items ranges from 33 to 165 and the higher the score, the more the foreign language anxiety (Talebnejad and Nekouei, 2013). Each item has a scale of five-point Likert scale ranging from 1) strongly agrees, 2) agree, 3) neither agree nor disagree, 4) disagree to 5) strongly disagree. Items $1,3,4,6,7,9,10,12,13,15,16,17,19,20,21,23,24,25,26,29,30,31$, and 33 represent high anxiety, while items 2 , $5,8,11,14,18,22,28$, and 32 show lack of anxiety.

\subsubsection{Beliefs about foreign language inventory (BALLI) Questionnaire}

Horwitz developed the Beliefs about Language Learning Inventory (BALLI) which is a means to determine teachers and students' attitudes toward a variety of issues related to language learning (Talebnejad and Nekouei, 2013). It has teacher and student versions in different item numbers but what is common is that each item has a five-point Likert scale ranging from 1 (strong agreement) to 5 (strong disagreement).The first version of BALLI had 27 Likert-scale items according to free-recall protocols of 25 language teachers who had different cultural backgrounds. They were asked to list not only their own attitudes toward language learning but also other people's beliefs, and their students' beliefs about language learning. The second version of BALLI consisted of 34 items across five main areas: foreign language aptitude, the difficulty of language learning, the nature of language learning, learning and communication strategies, and motivations. The point which is worth mentioning here is that in this version some items were added which were directly related to learner beliefs (items $12,15,18,23$, and 31 ).

BALLI versions contain statements, according to their theme or topic, related to the following categories:

1 - The difficulty of language learning: Items $3,4,15,25$ and 34.

2 - Learning and communication strategies: Items 7, 9, 13, 14, 18, 21, 22 and 26

3 - The nature of language learning process: Items 8, 12, 17, 23, 27 and 28.

4 -Aptitude for language learning: Items 1, 2, 6, 10, 11, 16, 19, 30 and 33.

5 - Motivation and expectations for language learning: Items 5, 20, 24, 29, 31 and 32.

Based on the level of agreement mentioned by respondents the items are ranged from 1 (Strongly agree) to 5 (Strongly disagree) (Talebnejad and Nekouei, 2013). In this study both teacher's and student's versions of BALLI were employed.

\subsection{Procedures}

As mentioned earlier, to select the required number of student participants, the QPT was administered to 130 sophomore university students majoring either in TEFL or translation. Then 60 students whose scores fell between 28 and 37 (intermediate level according to the test placement chart) were chosen, 30 males and 30 females. Meanwhile the researcher talked to 25 EFL teachers, and among these, 15 teachers who showed interest in completing the questionnaire were selected. 
In the next stage the students were given the FLCAS questionnaire to fill. They were told that they have enough time to answer all the questions in the questionnaire, and they were told that their answers will not be revealed to anyone anywhere and under no circumstances. After the FLCAS questionnaires were completed, the researcher collected them and told the students that she would return the next session for the other questionnaire.

In the next session the researcher administered the BALLI questionnaires. The same procedures followed for FLCAS questionnaire were repeated in the second session. After the BALLI questionnaires were filled out, the researcher collected them for later analysis.

Regarding the teachers, the researcher referred to their offices one by one and gave them teacher's version of the BALLI questionnaire to answer. Some of the teachers took the questionnaire and returned it within one week.

\section{Result}

\subsection{Investigating the First Null Hypothesis}

In order to check the validity of the first null hypothesis, the correlation between the two sets of questionnaires which were given to students had to be calculated. For this purpose, Pearson correlation coefficient was employed and the results are given in Table 1.

Table 1.The Results of the Correlational Analysis

\begin{tabular}{llcc}
\hline & & BALLI & FLCAS \\
\hline BALLI & Pearson Correlation & 1 & $0.699^{* *}$ \\
& Sig. (2-tailed) & & 0.000 \\
& $\mathrm{~N}$ & 60 & 60 \\
\hline FLCAS & Pearson Correlation & $0.699^{* *}$ & 1 \\
& Sig. (2-tailed) & 0.000 & \\
& $\mathrm{~N}$ & 60 & 60 \\
\hline
\end{tabular}

**. Correlation is significant at the 0.01 level (2-tailed).

As can be seen in Table 1, the correlation between the two sets of questionnaires, that is, BALLI and FLCAS, is high enough $(r=0.699)$ to be significant at probability level of $p=0.000$. Therefore, the first null hypothesis which states that, "There is no relationship between Iranian university students' level of anxiety and their beliefs about FLL" can safely be rejected, and it can be claimed that there is a positive and statistically significant correlation between students' beliefs about FLL and their level of class anxiety.

\subsection{Investigating the Second Null Hypothesis}

For the second null hypothesis the students' responses to the student BALLI questionnaire had to be compared with the teachers' responses to teacher BALLI questionnaire. Table 2 indicates the descriptive statistics for this comparison and Figure 1 illustrates the means graphically.

Table 2. Descriptive Statistics for Hypothesis Two

\begin{tabular}{lcccc}
\hline Group & $\mathrm{N}$ & Mean & SD & SEM \\
\hline Teachers & 15 & 4.05 & 0.228 & 0.059 \\
Students & 60 & 3.72 & 0.226 & 0.029 \\
\hline
\end{tabular}

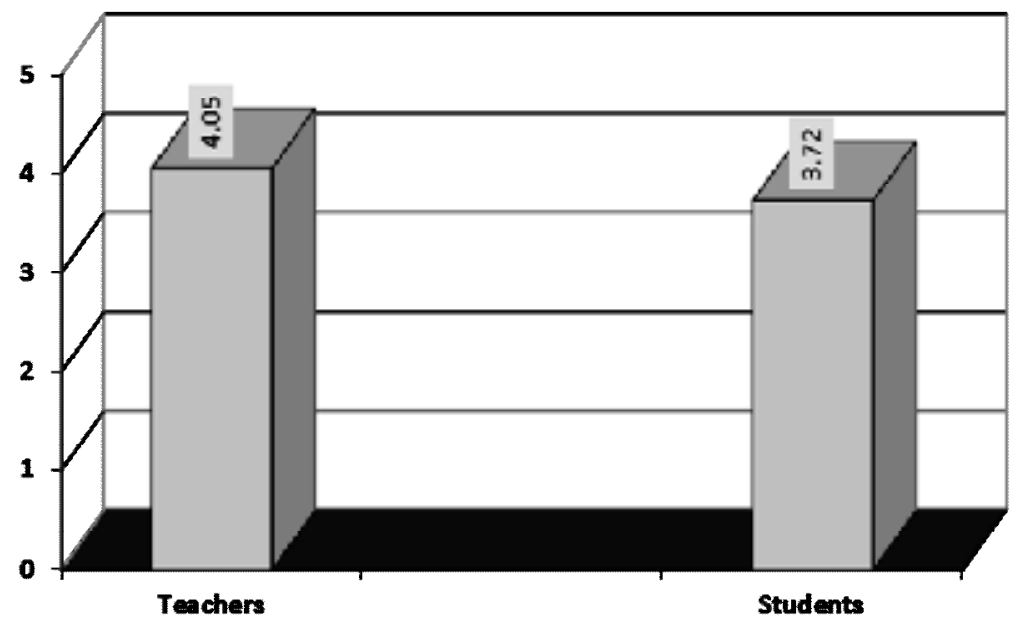

Figure 1.The graphical representation of the means for hypothesis 2 
It can clearly be seen in Table 2 that the means of the two groups are different. In order to understand if this difference is statistically significant or not, and since the number of the participants in the two groups was not equal to run chisquare test, an independent-sample t-test was run. Table3presents the results of the t-test.

Table3.The Results of the Independent-Sample t-test for Hypothesis Two

\begin{tabular}{cccc}
\hline $\mathrm{t}$ & $\mathrm{df}$ & Sig. & Mean Difference \\
\hline 5.128 & 73 & 0.000 & 0.33 \\
\hline
\end{tabular}

According to Table 3, the amount of t-observed (5.128) is significant at the probability level of $p=0.000$ which denotes a statistically significant value. Therefore, the second null hypothesis stating that, "there is no significant difference between Iranian university students' beliefs about FLL and those of their teachers" can also be rejected, and it can be said that teachers and students hold different beliefs about FLL.

\subsection{Investigating the Third Null Hypothesis}

The third null hypothesis entailed the researcher to compare the class anxiety of male and female participants. To do so, the males' and females' participants' responses to FLCAS questionnaire had to be compared. Table4 indicates the descriptive statistics for the FLCAS questionnaire, and Figure 2 shows the means graphically.

Table 4. Descriptive Statistics for Hypothesis Three

\begin{tabular}{lllccc}
\hline Questionnaire & Group & $\mathrm{N}$ & Mean & SD & SEM \\
\hline \multirow{2}{*}{ BALLI } & Male & 30 & 3.81 & 0.205 & 0.037 \\
& Female & 30 & 3.65 & 0.191 & 0.035 \\
\hline \multirow{2}{*}{ FLCAS } & Male & 30 & 3.62 & 0.181 & 0.033 \\
& Female & 30 & 3.90 & 0.220 & 0.040 \\
\hline
\end{tabular}

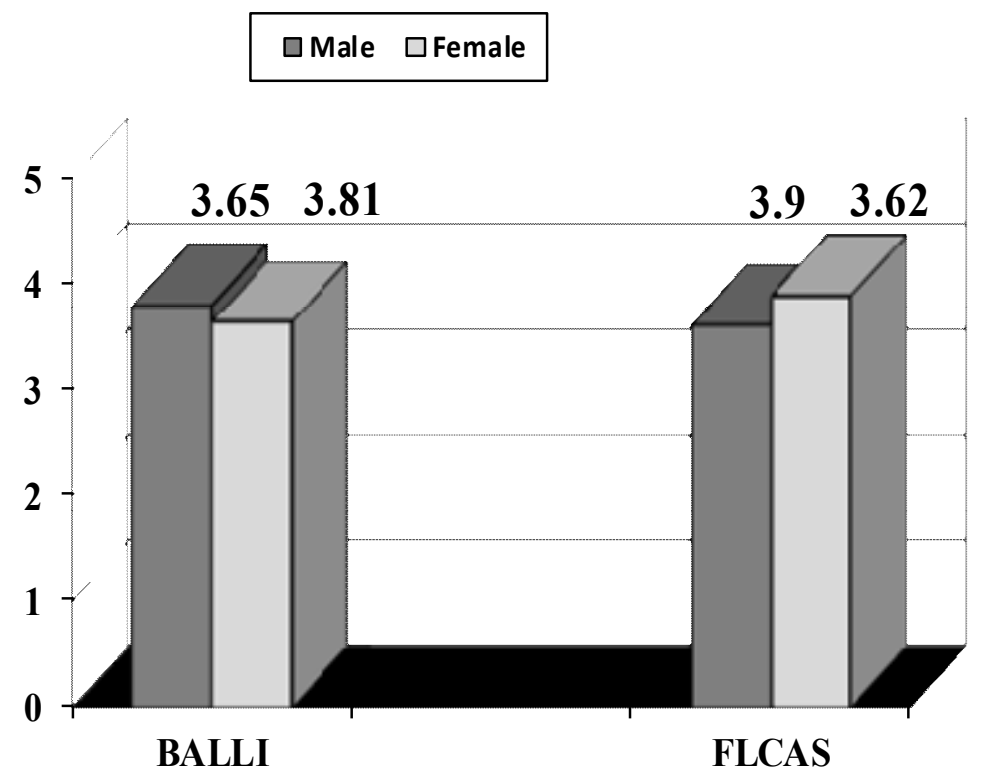

Figure 2. The bar chart for hypothesis three

By investigating Table 4, one can see that there are some differences between the mean of the male group and that of the female group. To find out whether this difference is just normal or it is because of the group difference, another t-test was employed. Table 5 gives the results of this t-test.

Table 5.The Results of the Independent-Sample t-test for Hypothesis Three

\begin{tabular}{rcccc}
\hline Questionnaire & $\mathrm{t}$ & $\mathrm{df}$ & Sig. & Mean Difference \\
\hline BALLI & 3.141 & 58 & 0.003 & 0.16 \\
\hline FLCAS & -5.368 & 58 & 0.000 & -0.26 \\
\hline
\end{tabular}


By investigating the data in Table 5, it can be understood that the amounts of t-observed (BALLI: 3.141, FLCAS: -5.368 ) are high enough to be statistically significant (BALLI: $p=0.003$, FLCAS: $p=0.000$ ); therefore, it can be concluded that males and females participants do not hold the same idea regarding class anxiety and belief about FLL. As a result, the third null hypothesis which states that, "there is no difference between male students' and female students' anxiety level and beliefs toward FLL" can be rejected, too.

\section{Discussion}

The findings of our study showed that there was a positive correlation between students' beliefs about FLL and their level of class anxiety. The more anxiety the students have, the more negative attitudes they have toward language learning. Investigating the relationship between beliefs about FLL and class anxiety among Iranian children learners of English, Talebinejad and Nekouie (2013) found a positive correlation that is in line with the result of this study. Moreover, Wang's study (2005) supports the result of this study, as far as the relationship between beliefs about FLL and class anxiety is concerned.

Second, the finding in our study showed that males and females participants did not hold the same idea regarding class anxiety and belief about FLL and it was shown that female students experienced higher level of anxiety than male students.

Regarding the findings of this study and the findings of other studies conducted on the role gender and classroom anxiety, conflicting evidence is available. For instance, Mersi(2010) provides supporting evidence to the finding of this study on the relationship between gender and classroom anxiety. However, Nahavandi (2013) and Hu (2008)report that classroom anxiety is not related to gender.

Finally, the findings of our study showed that teachers and studentshave different beliefs about FLL.In different studies Buyukyazi (2010), Peacock (1998), and Banyaand Cheng (1997) showed that there is a match or mismatch between learners'and teachers' beliefs toward FLL.

\section{Conclusion}

Despite the fact that most other studies of foreign language anxiety and beliefs concentrated on only one of these two areas, and mostly focused on the level of anxiety among university or high school or children FL learners, this study focused on four things: FLCAS, BALLI, male and female university FL learners, and teachers. On the basis of the findings of this study which were obtained based on the learners' answers to FLCAS questioner and both teachers' and learners' answers to BALLI questioners, several conclusions can be drawn. First of all the results revealed that there was a positive and statistically significant correlation between Iranian university students' beliefs about FLL and their level of class anxiety. Second, males and females participants did not hold the same idea regarding class anxiety and the beliefs about FLL. Finally, the findings provided evidence that teachers and students hold mostly different beliefs about FLL despite the existence of some similar beliefs. In other words, the results of this study indicated that males and females FL learners experienced different language anxiety and this anxiety could affect the beliefs of these learners toward FL learning.

\section{Implications}

The findings of this study bring several important pedagogical implications for foreign language teaching and learning. It seems that the educational administrators, curriculum designers, and practitioners involved in the Iranian educational foreign language learning system can benefit from the results of our study.

\section{Suggestions for Further Research}

Based on the findings of this study, a number of areas have emerged for future research. In other words, for further studies there are several different aspects which can be studied. First of all, the only two instruments used in this study were original FLCAS and BALLI questionnaires; that might not be enough. Therefore, it seems that in order to obtain richer data about anxiety and beliefs, it is better to supplement these two instruments with observations, interviews, and face-to-face interactions. In this study, individual differences such as personality, parents' pressure, peer competition, first language, religion, family background, and future plans have been ignored and it is worth trying to see whether or not these factors can play a role in learners' anxiety and beliefs toward foreign language learning. Another suggestion for future research is the investigation of the changes in learners' anxiety and beliefs about language learning over a period of time.

Before making any generalizations, and in order to validate the findings, this study can be replicated with larger sample size groups with different majors from different universities in different areas, especially all over Iran. Another factor which can be considered in future studies is related to context specificity. The point here is that our study was conducted at a non-state university (Azad University of Shahreza), so the other studies can be run at state universities.

\section{References}

Arnold. J., and Brown, H. D. (1999).A Map of the Terrain.In J. Arnold (Ed.), Affect in language learning (pp. 124).Cambridge: Cambridge University Press.

Banya, K., and Chen, M. (1997).Beliefs about language learning - A study of beliefs of teachers' and students' cultural setting. Paper presented at the 31 st Annual Meeting of the Teachers of Speakers of Other Languages, Florida. 
Büyükyazi , M. (2010). The beliefs of university foreign language students and their teachers about language learning.Celal Bayar Üniversitesi, Yabancı Diller Bölümü̈sosyalBilimler 8/1 (2010)s.169-182 169.Retrieved in 2013 from: http://sbe.cbu.edu.tr/dergi7/14Buyukyazi.pdf.

Gomari, H. and Lucas, R.I., (2013).Foreign language learning motivation and anxiety among Iranian students in the Philippines.Philippine ESL Journal, 10.Retrieved in 2013 from: www.philippine-esl-journal.com/V10-A6.pdf.

Horwitz, E. K. (1983). Beliefs about language learning inventory.Unpublishedinstrument.The University of Texas at Austin.

Horwitz, E. K. (1985). Using student beliefs about language learning and teaching in the foreign language methods course.ForeignLanguageAnnals, 18(4), 333-340.

Horwitz, E. K. (1986). Preliminary evidence for the reliability and validity of a foreign language anxiety scale.TESOLQuarterly, 20, 559-564.

Horwitz, E. K. (1987). Surveying student beliefs about language learning.In A. Wenden and J. Rubin (Eds.), Learner strategies in language learning (pp. 119-129). London, UK: Prentice-Hall International.

Horwitz, E. K. (1999). Cultural and situational influences on foreign language learners' beliefs about language learning: A review of BALLI studies. System, 27, 557-576.

Horwitz, E. K. (2001). Language anxiety and achievement.Annual Review of Applied Linguistics 21, 112-126.

Horwitz, E. K., Horwitz, M., and Cope, J. (1986).Foreign language classroom anxiety.Modern Language Journal, 70, 125-32.

$\mathrm{Hu}$, I. G. (2008).Foreign language classroom anxiety and gender difference. Northeast normal university, chi-lin. Retrieved in 2013 from: http://gjm.chsnenu.cu/2008/uploadfile/2007399253528.doc.

Hurd, S. (2007). Anxiety and non-anxiety in a distance language learning environment: The distance factor as a modifying influence. System 35, 487-508.

Liu, M. (2007). Anxiety in oral English classrooms: A case study in China. Indonesian Journal of English Language Teaching, 3(1), 119-137. Retrieved from: www.citation.itb.ac.id/pdf/...1\%20MEI\%202007/_201.

MacIntyre, P. D. (1995a). How does anxiety affect second language learning? A Reply to Sparks and Ganschow,Modern Language Journal, 79, 90-99.

MacIntyre, P. D., and Gardner, R. C. (1994).The subtle effects of language anxiety on cognitive processing in the second language.Language Learning, 44, 283-305.

Mak, B. (2011). An exploration of speaking-in-class anxiety with Chinese ESL learners.System 39, 202-214.Retrieved in 2013 from: www.sciencedirect.com.

Mesri, F. (2012).The relationship between gender and Iranian EFL learners' foreign language classroom anxiety (FLCA).International Journal of Academic Research in Business and Social Sciences, 2(6), 147-156. Retrieved in 2013 from: www.hrmars.com/admin/pics/841.pdf.

Nahavandi, N. (2013).Foreign language learning anxiety among Iranian EFL learners along gender and different proficiency levels.Language in India 13, 133-161.

Nikitina, L. and Furuoka, F. (2006).Re-examining Horwitz's beliefs about language inventory (BALLI) in the Malaysian context.Electronic Journal of Foreign Language Teaching, 3(2), 209 219.Retrieved in 2013 from: www.eflt.nus.edu.sg/v3n22006/nikitina.htm.

Ohata, K. (2005). Potential sources of anxiety for Japanese learners of English: preliminary case interviews with five Japanese college students in the U.S. TESL-EJ, 9(3), 1-21. Retrieved in 2013 from: www.tesl-ej.org/ ej35/a3.pdf.

Peacock, M. (1998). The links between learner beliefs, teacher beliefs, and EFL proficiency.Perspectives, 10(1), 125159.

Scovel, T. (1978). The effect of anxiety on foreign language learning: A review of the anxiety research. Language Learning, 28, 129-142.

Serraj, S., and Noordin, N. (2013).Relationship among Iranian EFL students' foreign language anxiety, foreign language listening anxiety and their listening comprehension.Retrieved in 2013 from: http://connection.ebscohost.com/.../listening-comprehension.

Subas1, G. (2010). What are the main sources of Turkish EFL students' anxiety in oral practice? Turkish Online Journal of Qualitative Inquiry, 1(2), 29-49. Retrieved from: www.tojqi.net/...1_2/TOJQI_1_2_Article_3.pdf.

Talebinejad, M. R. and Nekouei, R. (2013).The relationship between foreign language anxiety and belief toward FLL among children EFL learners.Basic Research Journal of Education Research and Review2(3), 49-54. Retrieved in 2013 from: http//www.basicresearchjournals.org.

Wang, N. (2005). Beliefs about language learning and foreign language anxiety: A study of university students learning English as a foreign language in Mainland China. A Published M. A. Thesis, University of Victoria.Retrieved from :http://www.asian-efl-journal.com/thesis.php.

YousefiAzarfam, A.A., and Baki.R. (2012).Exploring language anxiety regarding speaking skill in Iranian EFL learners in an academic site in Malaysia International Journal of Applied Linguistics and English Literature 1(2), 153162.Retrieved from: www.ijalel.org/pdf/67.pdf. 